\title{
Reflecting and Integrating the Contextual Influences of Ambiguities and Institutional Power in Organisational Research Design: A Case of Myanmar
}

\begin{abstract}
Our understanding of how an organisation operates is elucidated by the host country's political system. Myanmar has remained abstruse to researchers for many decades, as do most emerging markets prior to their transition from a centrally planned economy to a market economy such as China. We establish how the problematising and contextualisation of the methodologies adopted during a longitudinal fieldwork in Myanmar (2008 to 2016) has influenced our research focus and question. By reflecting on our experience of conducting organisational research in a highly institutionalised environment, we have identified limitations in the prevalent research methodologies used by the extant literature. Such methodologies tend to be incompatible with the Asian context. This process of problematisation required us to remain flexible and adaptive during the process of the generation of the research questions. We adopted a context-informed theory-building process and reflect on the interplay between interviewer, interviewees and local institutional contexts. An important insight from this process was the need to nullify the asymmetry of power between the interviewer and interviewees to obtain honest responses rather than superficial data that aimed to satisfy and please the interviewer/institutional context.
\end{abstract}

\section{Introduction}

Researchers from different epistemological perspectives are influenced by Western theories in organisational research, even when the context may be Asian emerging countries (Tsang, 2009). The rationale for conducting such research is based on gap-spotting in the literature or identifying research questions which have not been answered in that context. As a result, when the required data is not available to conduct the research or when the results do not conform to the preconceived assumptions of the researcher, these instances are seen as an inconvenience, often viewed as problems to overcome in order to reach the expected results or as a reason to discontinue research (Wu et al., 2016;Coase, 1992). In the existing literature on corporate governance, we observed that the same theories have been tested and validated continuously even though the context changes (Hassan, 2008; Hassan et al., 2012;ElKelish and Hassan, 2015). In some instances, important research questions remained unanswered because they were never even attempted (Coase, 1992). This is most obvious in countries such as Myanmar, which was not recognised nor explored before its political reforms in 2010 (Korybko, 2015). Dewey (2002) attributed such phenomena of habit to the nature of humans, who often rely on unthinking behaviours when they encounter a new situation because it allows for an economisation of effort. It is in such instances, Sandberg and Alvesson (2011) argued, that there is an opening for powerful insights and the possibility for alternative explanations and creative research approaches.

Since 2013, Myanmar has been regarded as an emerging market by the International Finance Corporation (IFC), a member organisation of the World Bank Group (2013). Organisations have paid exorbitant prices to acquire a macroeconomic glimpse of market conditions and the investment climate, as well as the sectoral and subsector analyses in Myanmar. These reports can be found in business events for investment, but they are expensive and not available in the public domain. Conversely, academic studies on Myanmar have been mostly confined to dissertations and seminar papers, which are rarely widely published (Than, 2014). Our understanding of how an organisation operates in a country is associated with the country's political systems. In Myanmar, our understanding is opaque because the country has been isolated from the international research community for decades, despite their recent transition from a centrally planned economy to a market economy such as China. This makes the institutional context of Myanmar perplexing which, in turn, poses interesting challenges related to formulating the research questions and identifying appropriate research approaches.

Though Alvesson and Sandberg (2011) described 'problematisation' as a way of formulating research questions, there has been limited empirical demonstration of how this process could be applied, especially in the context of an isolated, underdeveloped state such as Myanmar. We found that when applied to the context of Myanmar, the reflective process of problematising requires careful recording 
and reflecting on a researcher's on-going practical experience within a highly regulated institutional environment. Our research evidenced that problematisation can be a time-consuming, reiterative, and reflective process, which many researchers have subconsciously or consciously avoided prior to or during the conduct of a new research project. We wish to demonstrate that, despite the additional time and effort the process may require, problematisation can help us challenge unreflective, yet dominant, research assumptions and identify meaningful, important, and practical research questions. The broad issue we will use as an example in this paper relates to the banks' reactions on Myanmar's governmental policies of credit allocation; policies which are often incompatible with the banks' internal objectives.

By problematising our adopted research paradigm through reflective practice from the beginning of our 8-years research journey (from 2008 to 2016), we experienced a number of shifts in paradigmatic positioning. As we started data collection, the fieldwork experience challenged our assumptions. As the understanding of our research scope changed alongside the data we obtained (or were unable to obtain), our research questions were increasingly refined. As a result, we ended up reflecting on the compatibility of Western management theories such as institutional theory and Oliver's (1991) strategic responses to institutional pressures in an emerging market. Furthermore, by reflecting on our own experience of conducting organisational research in a highly institutionalised environment, we questioned the prevalent modes of research that dominate the Western literature (Simonds and Christopher, 2013). These dominant research modes may be incompatible with the Asian context, which has a significantly different institutional environment. We provide supporting evidence that researchers should identify appropriate research methods and research questions by deeply contextualising their research to the emerging markets' characteristics (Tsui, 2007).

The consideration of institutional context leads us to section 2 where we provide an account of the challenges we faced when adopting a wide range of research methods in the context of Myanmar, and how reflective practice was used to address such challenges. By being reflective of our experience at every stage of the research, we provide an account that we hope will encourage researchers to develop context-informed, theory-building and -testing approaches rather than applying unreflectively the Western management theories in emerging market contexts (Meyer, 2006; Shapiro et al., 2007; Welch et al., 2011). In section 3, we provide a practical account of the application of our reflective practice in research, followed by the discussions and conclusion in Sections 4 and 5 respectively.

\section{Generating 'Practical' Research Questions and Identifying the Appropriate Methodology}

Research paradigms are recognised as consisting of specific epistemological stances and belief systems that influence how research questions are answered (Morgan, 2007;Kuhn and Hacking, 2012). They provide social scientists with a coherent understanding of a particular set of assumptions regarding the nature of knowledge and the appropriate methods of producing such knowledge (Malmi, 2010). For example, social science positivists view knowledge and Truth as objective and tangible and use methods akin to those used within the natural sciences (Gray, 2017). Positivism argues that reality exists external to the researcher and it can be investigated through the rigorous process of scientific inquiry. On the other hand, interpretivists reject the view of human knowledge as external. "Truth" and meaning do not exist in an externalised world, but are created by people's interactions with the world. Meaning is constructed, not discovered, so the subjects construct their own meaning in different ways, in relation to the phenomena observed. In interpretivist paradigms, multiple and contradictory, but equally valid, accounts of the world can co-exist. Researchers have to study social actions, objects and society from the perspective of the person observed. By adopting a positivistic or interpretivist stance, researchers have to adjust their chosen research design, and the processes applied to the data collection, analysis and synthesis.

The established literature in a discipline dictates to scholars what the appropriate research questions are, and what the future scholars should study including what methodologies should be used. Thus, the discipline, implicitly or explicitly, may dictate what the scholars' research paradigm should be, rather than allowing the scholars to develop epistemological understandings of the world that reflect their personal research paradigms (Creswell, 2003). It can be difficult to challenge the pre-existing epistemological assumptions of a discipline or research field because it means questioning the existing powers within that scientific field (Alvesson and Sandberg, 2011). Starbuck (2006) and Alvesson and 
Sandberg (2011) commented that this fear of pushing the boundaries of an existing paradigm has contributed to the scarcity of interesting and influential theories. Adopting a different approach can upset one's colleagues, reviewers and editors and, therefore, may reduce the chances of publishing. However, such behaviour may also lead the researcher to overlook the underlying problems in practice, as the researcher follows unreflective research routines (Alvesson and Sandberg, 2014). Thus, Daft and Lewin (2008) emphasised the need to prioritise new theories and ways of thinking about organisations, coupled with a plausible methodology grounded in theory, over a vigorous application of rigorous research methods. By focusing on the latter, one could hinder new theory development and an understanding of the wider contexts.

Alternative paradigms have emerged throughout the years to address the limitations of the dominant paradigms (Denzin and Lincoln, 2011). One such paradigm is 'pragmatism'. scholars who conduct research from a pragmatist perspective, orient themselves toward solving practical problems (Creswell and Clark, 2017). In the next section we provide a more detailed account of pragmatism and its importance in conducting research in the emerging market context.

\subsection{Is Pragmatism an Alternative to Dominant Research Paradigms?}

Both positivism and interpretivism, the dominant paradigms in social science research, involve fairly strict applications of content to situations that are specialised, firmly bounded, scientific and standardised (Schon, 1987). This causes social processes and institutions to be objectified without critical examination, thereby reinforcing and reproducing any implicit status quo (Ross and Lynne, 1986). Dewey (1925) identified these paradigms as having commonalities because they seek to identify a truth irrespective of whether it is subjective or objective. The adherence of the paradigms' methodologies and epistemologies can lead to a search for truth, which effectively removes critical interpretation from the research findings. However, our critique of the dominant paradigms in corporate governance research of emerging markets is not an attempt to discredit them. Instead, we adopt a similar stance to Malmi (2010) and Quattrone (2009), we argue that: when we make unquestioned assumptions, we fall into the realm of mystical belief and religion. However, it can be difficult to challenge our assumptions due to our human nature, we tend to do things based on habitual behaviour. By habit, Dewey (2002) refers to the ways of doing things that have become fully embedded. This includes methods for solving problems, pursuing aims and looking into the techniques of practice. Habits arise due to the economisation of effort through applying routines which have proven to be successful in the past. This saves people the trouble of figuring out new responses each time that they encounter a situation (Gross, 2018) and allows them to take advantage of collective learning, to establish interrelatedness and to achieve legitimacy within the particular field of study.

Pragmatism's views of the measurable world are related to Dewey's (1925) concept of experiential reality. He referred to the experiential world as having different elements or layers, some of which are objective, some are subjective, and some a mixture of both. The layers may be stable or precarious; may be complete, orderly, recurrent as well as controlled, ambiguous and indeterminate. One methodology may not be suitable to observe and measure the multiplicity of layers. The pragmatist paradigm allows, even prefers, mixed methods and a diverse range of approaches when researching a phenomenon. Both objective and subjective knowledge can be acquired through multiple approaches, which are based on 'what works' (Creswell and Clark, 2017). Feilzer (2009) argued that those who choose to conduct research using a pragmatist approach have a libertarian tendency of wanting to be free from the mental and practical mind-forged manacles of the research routines imposed by the dominant paradigms. Thus, pragmatism appears to be ontologically agnostic and epistemologically tolerant leading many scholars to consider pragmatism as a methodological approach and not a paradigm (Feilzer, 2009;Morgan, 2007). Where positivism argues that there is a single objective reality to any research phenomenon or situation regardless of the researcher's perspective or belief, interpretivists accept the existence of multiple realities which are perceived through people, therefore, subjective (Guba and Lincoln, 1994; Neuman, 2000). However, pragmatists do not find the question of reality as interesting and are more concerned with the ontological realities of the people involved in an environment under observation. They are interested about the appropriateness of the research approaches rather than applying dominant research methodologies in a discipline without questioning their compatibilities to 
a particular context or naively assuming that the collected data as a presentation of a reality (Alvesson, 2003;Bailey et al., 1997). Unlike the positivists who rely on deductive reasoning and constructivists that focus on inductive reasoning, the pragmatist approach is based on abductive reasoning that moves back and forth between induction and deduction (Morgan, 2007). This means that knowledge accumulated from one method or instrument allows the researcher to inspect the situation, identify and state the problem, develop suggestions for addressing it and, eventually, reach a resolution (Biesta, 2010).

Tashakkori and Teddlie (1998) argued that those who deploy pragmatism consider identifying solutions to practical problems to be of primary importance - more important than either the method or the philosophical worldview that underlies the method. By problematising the question, there is the opportunity for researchers to critically reflect on the knowledge acquired from different approaches (Hébert, 2015). Research in practice as Dewey (2002) puts it, is not always a linear process. Researchers are not always clear about their research questions or aims which often have to be modified in an unpredictable manner during the research process because of indeterminate situations. As a result, those who advocate for pragmatism emphasise the need to apply reflective practice and be creative in responding adequately to indeterminate situations during fieldwork (Alvesson, 2003; Gross, 2018; Dewey, 1925). Nevertheless, although there are a number of papers providing theoretical discussions on the merits of pragmatism in research, there have been limited research papers demonstrating how it can be applied (Feilzer, 2009; Gross, 2018;Morgan, 2007;Alvesson, 2003;Watson, 2011; Wicks and Freeman, 1998). For instance, Alvesson (2003) suggested how pragmatism and selfcritique could allow researchers to avoid associating themselves with the belief that the data simply reveals reality. Thus, the researchers should interpret the meaning of empirical data arising from interviews creatively. Similarly, Riach (2009) highlighted the importance of self-awareness when conducting interviews. Yet, both authors focused on the data collection and interpretation process rather than the process of developing the research questions that guide the interview process.

Emerging markets, such as Myanmar, have been isolated from the international research community for decades. Consequently, as researchers, we would not know what research questions are important to explore and what research methodologies are appropriate. It is common, even though unacknowledged, that social science researchers will exclude context in their studies because of lack of data as it is the case in Myanmar, or they will adopt the information without a critical reflection of the research settings. For example, our first research question, which was to analyse the impact of regulatory policies on banks' credit allocations, was adopted based on prior literature. However, the challenge that we faced was the lack of available, reliable data to answer the research question. For some scholars, this indeterminate situation can be considered a reason to exclude Myanmar from their research (Wu et al., 2016). On the other hand, we continued our research by reflecting on our own experience and refining our research questions to understand the actual organisational and management practice, as related to banks' adoption and adjustment to regulatory policies while not compromising their profit maximisation objectives. Thus, the ability of a researcher to not only balance indeterminate situations but also overcome roadblocks through reflective practice is important in emerging market settings.

Therefore, in this paper, we have charted how our eight years' research journey took our research philosophy from positivism, to interpretivism only to finally end up applying Dewey's version of pragmatism (Dewey, 1937). Pragmatism has helped us grapple with the complexities of an institutional landscape which is ambiguous and unexplored. We were able to take into account the impact that we realised we had on that environment, and on the people who were the subject of our research. There are also the potential ramifications, intended but more often unintended, that our research has had on the communities that we investigated. This process has allowed us to identify and revise our original research questions into what Alvesson and Sandberg (2011) would define as 'interesting research questions'. By integrating this reflective process into our research design, we were able to push beyond the boundaries of the dominant research paradigms and identify practical research questions and issues that were insightful rather than producing and re-producing studies akin to past studies in the field. It is this reflective process that the next section will expand on and attempt to define. 


\subsection{Reflective Inquiry to Refine Research Questions and Choose Appropriate Methodology}

Reflective inquiry can be defined as an active, persistent and careful consideration of any belief or supposed form of knowledge, the grounds that support it and any further conclusions to which the inquiry intends to arrive at (Dewey, 1933). The reflection of oneself leads to self-knowledge. This is fundamental to the development of our professional practices (Kuit et al., 2001) because it allows one to solve and identify unique problems by spontaneously and seamlessly reshaping interpretations and a given course of action by evoking a repertoire of past professional experiences, images, successes, and failures (Bailey et al., 1997). The concepts of 'reflective inquiry' and 'reflective practitioner', which underpinned pragmatism as advocated by Dewey (1937), have been promoted as progressive and effective methods of practice in social studies (Ross and Lynne, 1986;Schon, 1987;Schön, 2017). Pragmatism involves decision-making in a socio-political context, the identification of problems, the search for satisfactory answers and the investigation of social problems as realised in the lives of individuals (Barr et al., 1977).

The research settings that researchers encounter during any fieldwork have the characteristics of indeterminate situations. However, reflective inquiry has not been promoted as an integral part of the organisational and management literature. There is a range of reflective models developed and applied in various disciplines over the years: to name just a few there are the widely-known reflective models developed by Kolb (1984), by Schon (2017) and by Gibbs (1988). All of these models are influenced by Dewey's process of 'learning by thinking on experience' (Burns and Bulman, 2000p. 4). Learning is presented as a process of trial and error, the result of eliciting intelligent actions or responses. These intelligent actions are made after the careful reflection of prior experiences and the choice of the correct actions among a range of possible lines of actions identified (Dewey, 2002). Similarly, researchers can reflect on the indeterminate situations that they encounter in the research process to generate practical research questions and to develop appropriate methods for knowing the unknown.

Kolb's (1984) reflective model occurs in four stages: concrete experience (doing/having an experience), cognitive reflection (reviewing/reflecting on the experience), abstract theorization (concluding/learning from the experience), and experimentation (planning/trying out what have been learned). Gibb's (1988) reflective model, which is an extension of Kolb's model (1984), is a cyclical one, where one can plan the actions for the next stage after carefully reflecting on the experiences encountered in the previous stage. Unlike Kolb's (1984) four-stage model, Gibb's (1988) reflective model is more detailed and consists of six stages: descriptions, feelings, evaluation, analysis, conclusion, and the action plan. In description stage, researchers should ask themselves who they were with, what they were doing, what happened, who else was with them, what role the other person played in the process and what the result was. This stage is followed by an analysis of the researchers' feelings. In the evaluation stage, researchers would evaluate the outcome by benchmarking against a standard, e.g. whether the data that researchers collected were reliable and viable to conduct quantitative analysis; whereas in analysis stage, researchers would analyse what went well or wrong, what contributed to these events and why might these things have happened. In conclusion stage, researchers would summarise all the events that occurred from different perspectives and what could have been done to change the outcome. Finally, in the last stage, researchers would develop a plan of action on what they should do if they encountered the same situation in order to have different outcome. These action plans will get implemented, and the process will begin again as required.

When choosing which model we would adopt for this study, both Kolb's (1984) and Gibb's (1988) reflective models seemed appropriate. However, their definitions of reflection have ex-post orientation, where one reflects on something that has transpired (Yanow and Tsoukas, 2009;Keevers and Treleaven, 2011). Their models do not explicitly promote critical thinking concerning the assumptions behind our actions during and after our research activities or the actions that a researcher has to undertake at different stages of the research journey. In other words, if we were to adopt the reflective models of either Kolb (1984) or Gibb (1988), we would only reflect after the end of a research activity rather than during the research activity. Some of the research activities that a researcher engages in require spontaneously adjusting in response to the research participants. For example, reflections can occur 
both during and after the end of every interview. Applying the reflective models that have implicit expost orientation would only allow us to reflect after the interview.

Thus, when we eventually adopted a pragmatist approach, we followed Schon's (2017) reflective model. Compared to the reflective models developed by Kolb (1984) and Gibbs (1988), Schon's (2017) model provides in-depth analytical reflection across the whole research process in two stages of action: reflection-on-action and reflection-in-action. Reflection-on-action is directed toward the action that is being carried out but when the action is interrupted (stop-and-think in the pause). Similar to the reflective models of Kolb (1984) and Gibbs (1988), reflection is directed towards the action after it has already been completed. For example, after an interview, a researcher could reflect on his/her experiences with the interviewee. They include whether the interviewee responded to researchers' questions; and if not, the researcher would analyse the events in more details, especially what went wrong and what contributed to the negative experiences. This could be done through comparing with the researcher's own experiences with previous interviewees. Afterwards, the researcher would make an action plan with an anticipation that they were to encounter similar negative experiences/indeterminate situations again.

Reflection-in-action is directed toward the action that is being carried out without interrupting the action itself. Yanow and Tsoukas (2009) identified reflection-in-action as a reflection that takes place 'in the moment', a phrase adopted from theatrical improvisation theory. Unlike reflection-on-action, that this type of reflection decreases the chronological and physical separation between reflection and action. Schon's (2017) argued that reflection-in-action is a more useful and realistic alternative to spontaneously solving problems and decision-making. Similarly, as researchers, though we may have done careful planning before every fieldwork, however, the field or the research environment itself is not static. We can encounter different forms of surprise which require immediate responses. For instance, researchers who conduct interviews, must adjust their actions such as non-verbal or verbal cues and rephrase their questions in response to the interviewees' actions and answers. Otherwise, there is a serious risk that the researchers will not be able to clarify any of the confusions after they leave the fieldwork.

We applied Schon's (2017) reflective model throughout the conduct of research from 2008 to 2016. Reflection-on-action took place at the end of every research activity. This included our reflection on the actions taken during and after the completion of each research round. This enabled us to explore the causes of the indeterminate situations that we experienced. Reflection-in-action took place during our interviews in Myanmar, i.e. Phases 2, 3 and 4 as shown in Figure 1. This included observing the interviewees, reflecting on our interactions with the interviewees, reflecting whether the questions that we asked were making the interviewees uncomfortable or whether we were receiving genuine responses to those questions and if not, what would be the best possible action to be taken to make them feel comfortable. This has been discussed in more details in Section 3.2. In both stages of reflection, we would ask the following questions: who we were with, what we were doing, what the context was, who else was with us (during the interviews), what role the participants played in the interview process and what the outcomes would be. We would describe and answer the questions as objectively as possible. This allowed us to think about what we would do if we encountered the same situation and wanted to prompt different outcomes, allowing us to plan for the next stage or to revise the research questions. These action plans were then implemented, and this process was repeated as required. 
Jul-13

Key Events in Myanmar Political and Financial Spheres

Political

Governance

Systems

Research

Timeline

Research

Questions

$1 / 01 / 2008$

Jan-09

Jan-10

What are the impacts of

repressive financial policies on

banks' credit allocations?

Phases

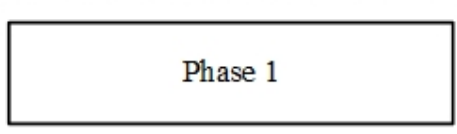

Research

Paradigm

Research

Methodology

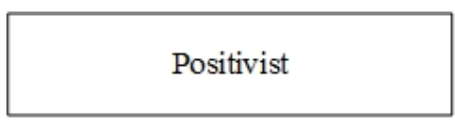

Quantitative cross-section research design using statistical data collection and analysis

Views on

Interviews

Researcher's Role

\section{Outsider}

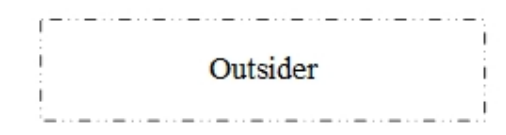

Nov-10 General Election

New Central Bank of Myanmar Law

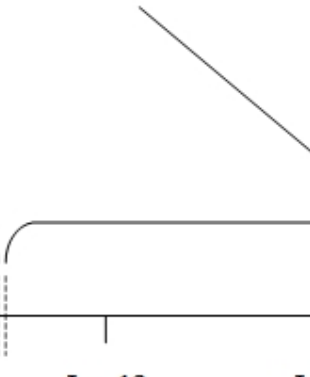

Jan-1

Jan-12

How do banks develop their

internal policies on credit allocations in response to financial policies?

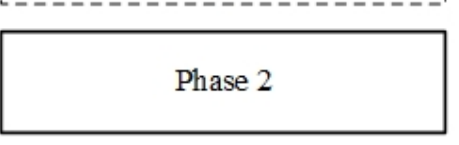

Interpretivist

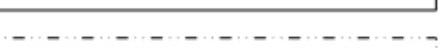

Qualitative cross-section research design using interviews

and thematic analysis

(n-

Neopositivist

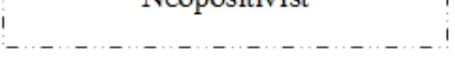

Outsider

Figure 1: Evolution of Research Journey in an Emerging Country
Mar-16

\section{New Financial Institutions of Myanmar Law}

Economic T ransition Under 15

Economic T ransition

Under The National League

the Military-Backed USDP

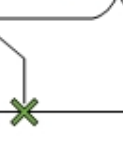

an-13

Jan-14

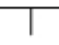

for Democracy

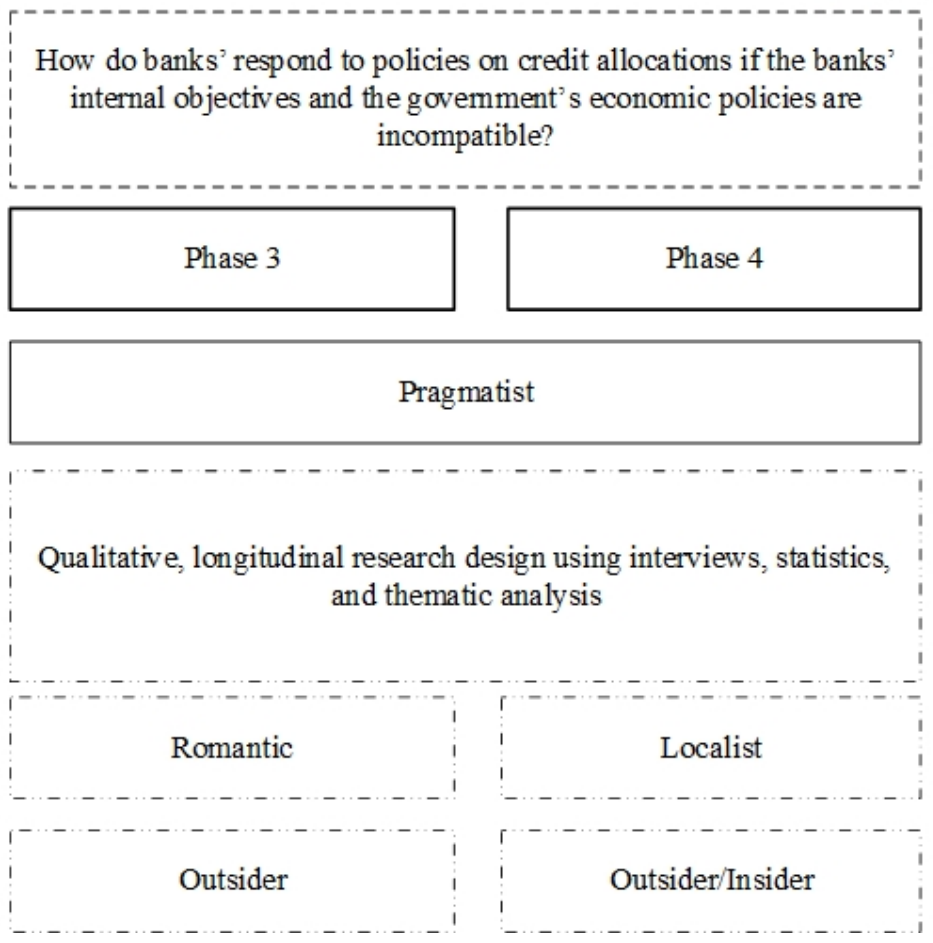

1/2017 
This reiterative reflective process led to a journey of paradigm discovery (see Figure 1). Early in our journey, we adopted positivism; a decision that was taken unreflectively dictated by the disciplines of macro-economics, banking and finance corporate governance and their related empirical literature, which is dominated by quantitative, positivist thinking. However, once we started conducting research in the field, we felt dissatisfied with the positivist epistemology and methodology. The results that we obtained from applying positivist epistemologies were meaningless and the dissonance between our findings and the quantitative indicators was too large to ignore. Consequently, we revised our research questions and adopted the interpretivist paradigm. This second step was taken after what we thought was careful and deliberate, and yet we realise in retrospect that it was still unreflective. The assumption that the polar opposite would work was wrong; interpretivism still did not fit the data patterns that were emerging from the field. There was something singular and ever-powerful in the influence the highly institutionalised environment of Myanmar exerted on the respondents and consequently, on the responses that we would receive; however, that singularity was bounded by the subjective perceptions of the participants of the research. It was only then that we closely reflected on our experiences in the field and the challenges that we faced with our respondents during each step of the research process. We experienced this ambivalence and the philosophical struggle between the dominant paradigms in current empirical research and our own personal belief systems, epistemologies, and experiences. Early on, we were not aware of the impact our paradigmatic positioning has had on the research problems and/or phenomena we were investigating, and the methodologies adopted. This experiential journey will be discussed in detail in section 3 .

\section{Demonstration of Applying Reflective to Identify Research Questions using Myanmar as an Example}

Myanmar was under the British colonial rule until 1948. In 1962, due to political instability and uprisings in the country, the government installed a military-backed caretaking government. However, the military refused to hand over authority and proceeded to rule the country as a one-party state. Until 1988, Myanmar's economy had a set of policies that were intended to support and sustain the government's position and benefits. During that period, the government introduced a socialist military governance system. It nationalised the private sector and introduced a command economy while isolating itself from the international community and refusing foreign assistance. For decades, Myanmar has not received much attention from international communities and researchers. In 1990, after a series of pro-democracy protests that started in 1988, the government organised an election where the National League for Democracy (NLD) won $81 \%$ of the seats in parliament. The military nullified it and refused to hand over power, placing the political leader of the party under house arrest. The government then introduced a market-oriented economic system in the first half of the 1990s. However, the economy was still run largely by the military and the government backed enterprises similar to the modern-day Chinese economy.

In this paper, we have decided to use a specific regulation related to the government-imposed restrictions on lending to illustrate the journey we undertook. In Myanmar, during our research period (2008 to 2016), banks were not allowed to lend without taking the land or building of the borrower as collateral. Furthermore, they were not allowed to provide loans of a size that was more than fifty percent of the collateral value. From the start, we used institutional theory to explore how the banks' lending practices were impacted by such restrictive regulatory requirements. This practice has been investigated and monitored throughout the eight years of longitudinal study and is the empirical subject matter that brings to life the evolution of our research journey. In corporate governance literature, the enactment of regulations is akin to the detailing of the concepts underpinning institutional theory; it assumes that the actors within a complex institutional system conform to institutional pressures to achieve legitimacy, though there might be differences in the values that exist. It also highlights the central role of the state and how the non-dominant groups accept its dominance, either through hegemony or coercion, and it achieves legitimacy regardless of the incompatibility of the state's goals vis-à-vis the non-dominant groups' values (DiMaggio and Powell, 1983).

Oliver (1991) argued that when organisations are faced with contradicting institutional inquiries or with differing institutional prospects in relation to their internal objectives, they adopt different strategic 
responses. These can be categorised as acquiescence, a strategy taken by a firm to conform to institutional pressures; compromise, where a firm tries to reduce the extent to which conformity is necessary; avoidance, a strategy in which a firm attempts to prevent the necessity to conform to institutional pressures; defiance, a strategy in which a firm's nonconformity to institutional pressure is openly admitted and manipulation, a strategy in which a firm actively responds to an institutional pressure where changes in the institution are the goal. Prior to our commencement of the research, we assumed that the banks would acquiesce to institutional pressures. During our research journey, we found that the banks did not precisely always conform to regulatory requirements if their profit maximisation values had to be compromised to achieve legitimacy.

In reflecting on our research journey, it is important to discuss the wider institutional landscape. Hence, a description of Myanmar's political and institutional environment has been provided in this section, shown in juxtaposition to the research journey.

\subsection{Identifying the Research Questions through the Problematisation of the Positivist Paradigm in Myanmar}

When we first conducted our research in 2008, Myanmar was still under the military regime. Banks, in general, regardless of the countries where they operate in, are confined within a highly institutionalised regulatory environment where conformity is expected to achieve legitimacy, a phenomenon that is further exacerbated in Myanmar due to the government's high levels of engagement with the economy. Due to the dominant hierarchical culture in management decision-making because of the banks' ownership structures, it was challenging for us to develop an appropriate research design. Relevant prior literature on corporate governance has been dominated by the positivist perspective, where statistical data has been used to apply econometric models to analyse the effectiveness of regulations on emerging markets (Wu et al., 2016;ElKelish and Hassan, 2015). Hence, we began our research with similar research questions as those set out in the prior literature to conduct corporate governance research in Myanmar, i.e. 'What are the impacts of repressive financial policies on banks' credit allocations?' In research based on positivism, it is usually a standard practice to use certain measurements based on the fact that they have been successfully employed by others in the literature (Granlund and Lukka, 2010). It provides efficiencies in academia and concerning the legitimacy of a research study within its discipline. Therefore, we tried to collect data such as the inflation index over the past years, as well as interest rate spreads and the credit allocated to different sectors.

However, the original fieldwork and data collection in 2008 led to a revision of the original research design due to our reflection-on-action which took place after every attempt to collect quantitative data. When we first collected secondary data through international developmental organisations, we quickly realised that the available secondary data was not reliable nor accurate. For example, we found that there were inconsistencies in the inflation data reported to the World Bank from 1995 to 2011 (Win, 2013). We also gathered other financial indicators from the International Monetary Fund (IMF), even though some of the data was only available from 2004 onwards. Such data was also inaccessible from Myanmar's central bank and other banks because they were considered to be confidential and thus, were not released publicly. During our discussions with government employees, we found that there existed complicated data reporting processes at both the ministerial and bank levels gathered in Myanmar's opaque socio-economic context. Furthermore, it was apparent that the people responsible for reporting the data were not following standardised formulas or calculations. In fact, the economic and financial indicators could have been manipulated to support a political agenda, similar to the way the Chinese government has manipulated its own currency (Truman, 2006). Thus, the first set of data had limited validity or credibility. The lack of well-structured statistical institutions and technology to provide accurate data added to the complexity involved in conducting the statistical analysis. The significant gaps in the baseline data and the unreliability of statistics appears to be a fact of life in Myanmar's context (Than, 2014;Kubo, 2012). This lack of reliable statistics for the quantitative research meant that we were not confident in conducting econometric modelling techniques using crosssectional or panel data. We revisited the literature to explore other research methodologies that could be used. 
We soon noticed that some authors used the ease of access to finance by businesses to understand how banking regulations could have an impact through the banks themselves. For example, Beck and Demirguc-Kunt (2006) measured ease of access to finance using the demand for bank loans and the frequent use of bank loans in developing countries. Similarly, self-reported measures by businesses, such as applications for bank loans and overdrafts, successful applications and the number of rejections, have also been used in the literature (Xuegong and Xueyuan, 2011;Nanyondo et al., 2014). Therefore, we decided to change our unit of analysis from banks to businesses. This required us to conduct surveys with businesses to collect the primary data. Although we changed our data collection method, we still aimed to conduct our research within the positivist paradigm. In the second fieldwork in 2009, we aimed to indirectly measure the influence of the strict regulations on banks. We presumed that if the strict regulations were implemented by the banks, then the business owners would have difficulties in expanding or running their businesses. Hence, we changed our main research question, i.e. 'What are the barriers faced by businesses in accessing financial services?' One of the hypotheses that we made was that the levels of difficulties faced by businesses in access to finance would correlate with the size and annual turnover of these businesses. However, we were soon faced with new challenges: the businesses were not willing to provide the required information.

At this stage, we contacted businesses through our networks. Many of them refused to participate in the survey. There were some respondents who agreed to participate in the survey, but they did not provide accurate information related to their annual turnover, the actual amount of loans that they applied for and any other financial information. This led us to engage in another reflection-on-action and realise the underlying causes for not being able to collect the required information. Through our discussions with local businesses, we were told that we could be perceived as government agents collecting information for tax purposes in disguise. In Myanmar, many businesses and organisations operate within the informal economy (Turnell, 2011). They did not register their businesses, nor did they pay taxes. Even if they were registered businesses, many of them had different financial statements serving different purposes. They would keep their own private financial statements where they would record detailed information about their actual profits and expenses. They would also have financial statements where they would present their profits as being lower than the actual figure to provide to the government for official tax returns. In some cases, they would keep another financial statement where their profits were presented as higher than the actual amounts to get larger loan sizes. Subsequently, we discovered that small business owners perceived banks as unapproachable irrespective of whether they could meet the stringent lending criteria or not, unless if they had political connections. From small business owners, we garnered the public perceptions on the banking sector's efficiencies and accessibilities.

In summary, we learned two key lessons from conducting research using the positivist paradigm at this stage. Firstly, prior to our first fieldwork in 2008, we expected banking practices across Myanmar to be institutionalised through regulations. However, after our first two fieldworks in 2008 and 2009, we realised that if we were to understand the actual impact of regulations on credit allocations, we needed to approach those who were involved in making the internal organisational policies rather than utilising statistical data which was either non-existent or unreliable. Secondly, we learned that quantitative surveys with businesses would not allow us to answer our intended research questions due to the inherent culture of misreporting data. Hence, we decided that we needed to change our unit of analysis to the senior management of the banks. The sample would include directors, general managers and chief executive officers because we found that most of the decisions within the organisations were made at the top management levels. At the end of Phase 1, we revised our research question again, i.e. 'How do banks develop their internal policies on credit allocations in response to financial policies?' This decision marked our first shift from positivism to interpretivism (Holstein and Gubrium, 2005).

\subsection{Revisiting the Research Questions through Problematisation of Interpretivist Paradigm in Myanmar}

In 2010, Myanmar had already organised the first democratic election after 22 years, and the militarybacked Union Solidarity and Development Party declared victory. It was considered to be a historic incident, not only politically but economically. The new economic reforms, unlike the economic reform in the 1990s which started with detaining political activists, commenced with the release of the political 
prisoners including high profile political leader, Daw Aung San Suu Kyi. With such historic changes, soon after, the sanctions were lifted by the European Union and the US in 2013. Like other emerging markets, Myanmar is currently undergoing a political transition and has lower than average per capita income, providing opportunities for foreign investors. Therefore, Myanmar has experienced a significant increase in Foreign Direct Investment and has been labelled as one of the Asia's newest emerging markets (Nehru, 2015).

When we conducted the second phase of research, we followed the interpretivist paradigm and adopted interviews as the main tool for data collection. We were expecting that in the interviews, we would get different perspectives from different individual interviewees as per the interpretivist paradigm (Stoian et al., 2018). However, due to the high-power distance, we could not ask lower level managers or loan officers to answer our research questions. In order to arrange meetings with senior management, we needed to find a mediator who had institutional power amongst the senior management of the banks. The first challenge was getting access to interviewees who would be able to answer our research questions. We found, through our local personal contacts, a director of the Central Bank of Myanmar who arranged interviews with the senior management of the local banks. She was able to assist us in getting access to such high-power individuals as she was the person who was in charge of the banks' due diligence process.

Our target sample size was 10 to 15 carefully chosen interviewees; during the time of the study, i.e. between 2010 and 2014, from four domestic banks out of 21 banks representing 79 percent of the Myanmar's lending market. Myanmar's banking industry had an oligopolistic market structure. Our primary aim was to conduct interviews with the senior management from 10 private banks and 3 government banks. Hence, if we could conduct interviews with at least one person from each bank, then we would have collected data from the banks that represent 90 percent of the total market share. In other words, our first approach towards interviews could be described as taking neo-positivist position as argued by Alvesson (2003). This was because we attempted to establish a context-free truth about reality through following strict interview procedures. However, if we were to reflect on our action to gain access to interviewees, we had already started leaning towards the localist position, which argued for producing morally adequate accounts through drawing upon cultural resources (Alvesson, 2003). For example, we recognised the existence of high-power distance in the context, therefore, to gain access to the interviewees, we approached a director at the Central Bank to arrange interviews.

Before the first interview, we were not made aware of how the mediator introduced the researcher to the interviewees. The interviewer was introduced to the participants as a family member of the mediator. Therefore, the senior managers at the banks accepted the request from the mediator to meet the interviewer. We followed a research protocol in which we tried to distance ourselves as interviewers from interviewees. To ensure quality and trustworthiness of the data collected under an interpretivist paradigm, we asked for permission to record the interview (Denzin and Lincoln, 2000). We quickly realised that the first interviewee was not comfortable answering our questions and reluctant to share any information. As such, the first interviewee's responses were similar to those written in the regulatory guidelines when we asked how they adopted regulatory guidelines in their internal policies:

Interviewee: We only follow what the central bank wanted us to do. We followed the central banks' policies very strictly and that's our main priority.

Therefore, we did not get much information from him on how he would adopt and translate the regulatory guidelines. At times, he rejected answering the questions altogether and the interview ended up being very short, clocking only 20 minutes. When we were conducting interviews, we constantly reflected both the verbal and non-verbal responses by interviewees in reaction to our questions and actions (reflection-in-action). The interviewee's non-verbal language and his tone and pauses during the responses suggested to us that the internal policies on credit allocations were not always corresponding to the expectations from the government/regulators. After the end of the interview, we reflected on our actions to understand why we could not obtain appropriate responses.

We realised that there was a lack of transparency and a general unwillingness of the banks and governments to provide data. We deduced that personal connections played a significant role in gaining 
access to the right people, but the role of the mediator could have influenced the interviewees' perceptions of how the responses would be fed back to the authorities through the interviewer. In a sense, the credibility of the interviewer could have been compromised by the misrepresentation of the identity by the mediator. In addition, although we changed our approach and shifted from positivism to interpretivism, we did not factor in the role of ourselves as the interviewers and how the power imbalance could impact the interviewees. What became quickly apparent was that there were high institutional controls. This meant that there was a need to build trust with the banks to gather accurate and reliable information and to revisit our interview techniques before meeting with the second interviewee.

After reflecting on our own experience through reflection-in-action and reflection-on-action with the first interviewee, in the second interview, we decided that we would not do any recording. Instead, we agreed to take notes during the interview. It was a challenging task because we ended up multi-tasking. Our hands were taking notes, and our minds were preparing for the next question while analysing the content of the interviewee's responses, prompting while paying attention to the non-verbal behaviour. Despite us not recording the sessions, the interviewees would stop responding to our questions when we took notes of the process they used to translate the regulatory guidelines and disguise their nonconformities to regulatory pressures. It was clearly a sensitive process to expose:

Interviewer: Supposedly, you found this business which is going to have good profit and viable business, but it cannot provide enough collateral to increase the loan size. What would you do if the central bank told you that you should not lend more than 50 percent of the collateral value?

Interviewee: Well......we do sometimes reconsider our approaches.....you see, the property prices are always going up ....

From these delayed responses to our interview questions, we realised that there were some nonconformities in how the interviewees internalised the repressive regulatory policy guidelines on lending, especially regarding the collateral valuations. This led us to make another revision to our research questions, i.e. 'How do banks respond to policies on credit allocations if the banks' internal objectives and the government's economic policies are incompatible?'

Furthermore, consciously now, we decided to change our interview method from a neo-positivist to a romantic kind of interview, where we focused on establishing trust and rapport between ourselves and interviewees (Alvesson, 2003). From the third interview onwards, we conducted the interviews as informal chats rather than formal interviews. We could get much more detailed information as the interviewees felt more at ease that we were not recording them nor informing on them to the government. At the same time, we observed patterns of behaviour that did not fit the fundamental assumption in interpretivism that participants would have different understandings of the phenomena (multiple realities) (Stoian et al., 2018). However, there was a new challenge with this approach: developing the skill of remembering the interviewees' responses to the questions (Keightley, 2010). Qualitative research methods, especially from an interpretivist perspective, reject the idea of an 'absolute truth' (Denzin and Lincoln, 2000). In practice, we found that the whole research process was not straightforward and that the respondents in emerging countries, especially where there was high power distance, made it much more challenging to uncover even their "truths". The respondents would not reveal information on how they interpreted and/or concealed their non-conformities to the regulatory guidelines to us, the interviewers. Thus, even if we secured a full account of the contextual information to understand the role of institutions in shaping the banks' internal policies, we would not be able to get answers to our revised research question.

We realised that by using memory in data collection and analysis we had an advantage in exploring the relationship between public perception, institutional power and the role of agency during the institutionalisation process. The interviews conducted during this stage were a turning point for us to better understand the interplay between institutions and the banks (agents/actors). This is when our reflective interviewing technique commenced properly, as we constantly analysed our influence on the interviewees. The lessons from each interview were embedded in the following interviews. Subconsciously, we took a pragmatic turn as we observed our respondents' behaviour continuously. It 
was clear that we were still searching for truths and patterns, based on our praxis. Now, we know that the truth we pursued was with a small "t" and that we did not expect it to be as universalistic as our expectations were back in 2008, and yet, at the same time, it was not a pluralism of truths as it would have been within an interpretivist paradigm as there were clear commonalities in the behavioural patterns of our respondents.

We revisited Myanmar between 2010, 2011 and 2012. Despite all of our preparations, each visit had different surprises. The field was never static, and the process would never go quite as planned. By this time, we understood that we needed to reflect continuously on our data collection process and that advanced technical equipment such as recording devices or traditional tools such as pen and paper would not give us any advantage in exploring the respondents" "truths". It was our soft interview skills, the ability to be flexible and use the technical tools sparingly that allowed us access to the individuals' narratives. At this stage, we had already finalised our theoretical framework and our key research questions and we had established that the role of agency existed due to the conflicts between the banks' internal objectives and the government's policy objectives. We had also realised that if we were to explore sensitive information, then, the only tool that we could use was our memory and concentration for recording all of the information within a high-power-distance organisational and institutional environment. Consequently, by constantly reflecting on our interactions (reflection-in-actions) and experiences (reflection-on-action) with the interviewees, we realised that we had adopted a localist approach to interviews because we did not see interviews as data collection tools. Instead, we viewed them as empirical situations. This shift took place gradually from our earlier romantic position, where we still viewed interviews as tools for collecting data with the focus on interactivity and closeness to interviewees (Alvesson, 2003).

When we conducted the interviews as informal chats, the interviewees became more comfortable and we could gather an abundance of information. Though it may sound simple, for us, the actual data collection process was stressful. These interviews lasted between 90 to 180 minutes. We were developing themes, interpreting the information, exploring the historical causes behind their behaviours and triangulating their responses by rephrasing questions on the spot. The challenge here was to retain all of the information and being able to prompt the interviewees to give relevant information. We were challenged to remember all of the information after an interview. Therefore, we decided to write down all of the key information as soon as we reached a place where we could reflect on the information gathered. The longer the time that elapsed between the actual interview and reflecting on the account of the interview, the less the interviewer was able to recall all of the information (Keightley, 2010). This increased the risk of losing key information, which in turn would affect our data analysis. We found that we were able to recall the information one hour after the interview. However, the process became more challenging if the interviews were arranged back to back. Ideally, that should not be the case; however, as we had no control over the availability of the interviewees, we had to seize the opportunity whenever the respondents could give us an appointment.

Therefore, to assist in this process, instead of one person conducting an interview, we identified that we would need a research assistant during the process. The person would be collecting information rather than assisting the interviewer in asking questions. We also needed to pay attention to the fact that the person would be able to understand the government processes and the financial and accounting terminologies. We found a civil servant who could assist in the process. Interestingly, during the interviews, the person became a mediator rather than an individual assisting the process as sometimes he would know the interviewees beforehand and would focus on making them feel at ease with the research process itself. He neutralised the institutional power between the interviewer and interviewee because they had similar encounters and challenges due to working in the same institutional setting:

Interviewer: Hello Uncle $e^{i}$ this is (name). Thank you for giving me an appointment to interview you for my research. I would also like to introduce my uncle, He came with me to support my research.

Mediator: Hello Ko ${ }^{i i}$ (name). I came with her since she told me she needed some help in her research. I think I have met you before. You have attended the civil service training back in the 1980s, right?

Interviewee: Yes. I know you Ko (name). How have you been doing? It's been ages.... 
In summary, by reflecting in and on action, we realised that with the presence of the mediator, the atmosphere became more relaxed and the interview session went more smoothly. That was when we found that there were industry-wide accepted non-conformities or means to disguise non-conformities. One of which was done by inflating property prices to increase the loan size limits put on them by the central bank (Oliver, 1991). We were also introduced to other directors at the local banks. In this case, the mediator neutralised the asymmetry of power between the interviewer and interviewee. We did not disguise our roles as researchers. In contrast to the previous interviewees, the mediator assisted not only in retaining the information but also in developing a close relationship with different members of the various organisations. This process allowed us to build up rich and detailed organisational case studies. In this manner, we interviewed over 30 directors and managers. We learned that regardless of how close the relationship between the interviewers and the interviewees is, not using technology to record the interviews was always vital when capturing the interviewees' non-compliance to regulations. Gradually, without realising, we had adopted a localist approach to interviewing and our interviews became a naturally occurring social interaction, where the interviewer and interviewees were exchanging information in natural settings (Alvesson, 2003).

During this stage, we developed an interview protocol. After every interview, we reflected on our experiences (reflection-on-action), evaluated them against our research questions, analysed what could have been improved and looked at what went wrong. Then, we planned for the next stage of interviews based on the insights gained by our previous experience. Similarly, we paid close attention to the interviewee and the interview environment (reflection-in-action), to avoid making the interviewees uncomfortable. The reflective cycle only ended temporarily as the new reflective cycle would begin before the start of the next interview. By now, we have realised that we never fully subscribed to an interview process that fit the interpretivist paradigm. Nevertheless, our data analyses remained the same. All of our interviews were analysed according to the guidelines set out by Boyatzis (1998). The initial codes were based the institutional theory, and the emergent themes from the interviews were identified, analysed and rephrased as necessary. By allowing new themes to emerge rather than confining the themes to the theoretical framework, this also contributed toward developing practical research questions (Gioia et al., 2012). 


\subsection{Confirmation of our Reflections and Actions in Response to the Indeterminate Situations in Myanmar}

In 2013 and 2014, we analysed our data collected through the first two phases of the research. They included both descriptive and interview data. In 2015 and 2016, we conducted the next stage of interviews as an extension of the original theoretical framework that we designed back in 2010 and 2011. The research scope evolved, and we continued with our research on the banking sector in Myanmar. If we were to reflect on our interactions with the interviewees at this stage (reflection-onaction), the interviewees were more relaxed. By this time, Myanmar's financial sector has become more liberal and the political and economic environment has started transitioning from a planned economy to a market economy (Nehru, 2015). More Westerners and local researchers have become involved in exploring the organisational practices among banks (Nehru, 2015;Bissinger, 2014;Win, 2018). The interviewees even provided feedback to us about their interview experiences with the other researchers. They were surprised by the amount of paperwork that they were continuously asked to sign by researchers from European and North American research institutions:

Interviewee: These forms (research ethics forms) made me so uncomfortable. I was not able to read English properly. I did not know what was written on them. I had to ask my subordinates to translate them. I had to trust his words. The more papers I have, the more they made me uncomfortable.

As we were native researchers trained by Western research institutions, we could explain to them the need for all these agreements the different processes. We realised now, that over the course of our research from 2008 to 2016, we, as researchers, have transitioned from 'outsider' to partial 'insider'. The interviewees have by now become comfortable with the researchers because of the frequent encounters over a long period. Yet, they were still not comfortable with recording and taking notes. When asked about the reasons why they were uncomfortable, they mentioned that it was because they could not trust how the information would be used. One of interviewees from a government bank mentioned that there had been incidents where his ex-colleagues had been prosecuted for releasing confidential information. Hence, decision-making authorities were centralised and only those at the senior management such as those on the board of directors and general managers could approve loans. This included searching for business opportunities for their respective banks. Therefore, bank officers were merely performing administrative duties, as executive management exercise their authorities on more than assessing loan applications. It was not surprising that the government banks' employees had feared of prosecution as the Article 9 of the State-Owned Economic Enterprises Law, enacted on 31 March 1989 (immediately after the 1988 political uprising), states that:

Whoever is convicted of an offence of carrying out, without the permission of the Government, any economic enterprise prescribed under section 3 to be carried out solely by the Government shall be punished with imprisonment for a term which may extend to a period of 5 years and may also be liable to a fine. Furthermore, property both movable and immovable relating to the economic enterprise maybe confiscated.

Through reflecting our role in every research setting, we became more familiar with the interviewees by thoughtfully removing the feeling of perceived institutional power they felt in us, we enabled the build-up of trust. Without trusts and with the presence of high-power asymmetry, we would have obtained censored information, perceived to be legitimate by the institutional environment. Thus, we were able to confirm our perceptions of the existence of institutional power that we had in the beginning of our qualitative inquiries.

\section{Discussions}

Our transition from a positivist to a pragmatist approach appears longitudinal and intentional if one observes our research journey as shown in Figure 1. In the beginning, we started our research with the research questions dictated to us by the literature. Kuhn (1970) would have described this approach to selecting a suitable paradigm for a study based on identifying an 'exemplar'. By exploring the prior literature, new comers into the field were influenced by a group of practitioners who shared specific beliefs and practices. Consequently, we applied the positivist paradigm. Over the course of our research, 
we reflected on the experiences or indeterminate situations that we encountered, especially when collecting the quantitative data. This led us to revise our research questions. However, if we were to reflect on the actions whenever we faced indeterminate situations from 2008 to 2016, it was not an easy process for ourselves as researchers, trained in a discipline where the dominant paradigm is positivism. Furthermore, the only legitimate method to analyse data was statistical inference techniques. This difficulty was more evident when we tried to maintain our role as an outsider throughout the research process. We realised that we could not break away from the dominant paradigm immediately even when we discovered that the panel data were not reliable. For example, we changed the unit of analysis from banks to businesses as we continued to position ourselves within the dominant positivist paradigm. Our experience in the research process with the interviewees could be explained from an institutional theoretical perspective as well. However, in being persistent with the context which was unexplored and ambiguous, we discovered not only the appropriate research questions and practical approach to conducting a research in the highly institutionalised context but also ourselves as a researcher, i.e. how our own beliefs were different from shared beliefs among the members within the field of study. We believed that subconsciously, we were trying to achieve legitimacy in the field of our study and uncover Truth from the positivist perspective.

We persisted and thus, shifted our paradigm from positivism to interpretivism. We used interviews as a mean to collect the data and to answer our research questions. Yet, we still were not satisfied with the interviewees' responses to our questions because their responses were akin to regulatory guidelines. In both phases that took place in 2008 and 2010, we believed that objectivity in the data collection could be achieved merely by distancing ourselves from the research subjects under study. Even though our approach to the data collection changed, i.e. collecting panel data, conducting surveys, and interviewing, we realised that our shift to interpretivism was incomplete; we were still maintaining our position according to the positivist ontology. In other words, we tried to detach ourselves from the participants by creating distance. The influence of the 'self' in fieldwork and interviews has been recognised in disciplines such as anthropology, nursing and social work (Borbasi et al., 2005;Rapley, 2001). Scholars in organisational research tend to interpret interviews through a 'tell it like it is' approach and analyse the data by coding quotes with themes which could be derived from pre-existing theoretical frameworks or a grounded theory approach (Larsson et al., 2016;Carnochan et al., 2013;Borbasi et al., 2005). However, over the course of the research, by applying Schon's (2017) reflective model, we realised that it was impossible to assume that we had no influence on the respondents.

It might have been less problematic if the institutional powers in the organisations were limited; however, in an environment where there is a high-power distance, it is less likely for interviews to yield interesting data if we assume that we had no influence on the interviewees. Hence, instead of characterising Asian emerging markets as having lower institutional transparency and effective regulations for protecting minority shareholders, and a poor competitive environment resulting from a lack anti-trust and anti-monopoly legislation (Johnson et al., 2000;Laffont, 1998;Singh, 2003), we should take these aspects into account when identifying the appropriate research questions and research designs for conducting research in these countries. In other words, scholars studying organisational corporate governance practices in emerging markets from a positivist ontology could already be biased if they present and analyse the collected data as it is presented to them. In phase 1 and phase 2, it might seem like we did not get the required data, but we learned an important lesson, which is the need to identify the unspoken institutional rules, power and controls in addition to the appropriate research questions for our study. Over time, it was inevitable that we were in a subliminal space between an insider and an outsider due to the interpersonal relationships that we built with the interviewees. As discussed by Evered and Louis (1981), research done from an outsider perspective is more suited to developing timeless-truth statements. Thus, to our advantage, we could critically and systematically conduct research without being subject to 'conflicts of interest'.

Furthermore, as researchers from European research institutions, where there is a defined set of criteria for assessing the quality of our research, we faced many ethical dilemmas throughout the process in this context. For example, recording could have improved 'trustworthiness' of the data (Neuman, 2000), however it was perceived by the interviewees as demonstrating that the questioner had more 
institutional power. Similarly, though obtaining signatures from the participants on the consent forms was a way of meeting the ethical guidelines ( $\mathrm{Li}, 2008)$, it was perceived as transfer of power in terms of giving the interviewer the liberty to make vital decisions concerning their future though they were made aware of what the content of the form was through translations (Haworth, 2006). If a researcher is not familiar with the context (country and industry) that is being studied, then they can easily be led astray. Similar to other emerging markets, friends and familial relationships play a pivotal role not only in management decision-making but also in influencing accessing the right contacts to broaden the research participants. At the same time, if the institutional power borrowed from the mediator by the interviewer was not addressed, then we would not have been able to get responses to our research questions. Therefore, it became important to neutralise the asymmetry of power between the interviewers and interviewees. This is because the interviewers' behaviour and actions can imbalance the power between them. Through the reflective process, we understood that while we were maintaining research protocols to achieve legitimacy from the institutions that we belonged to, they were also trying to maintain similar positions with their respective institutions. In other words, we need to recognise that in a research environment, not only the research participants but also the researcher is experiencing institutional power, which may come from different sources.

We would like to highlight the importance of the political environment related to the interviewees in relation to providing sensitive information and concerning their collaboration with our research. In the beginning of our research journey in 2008 , the banks were tightly regulated as a result of the banking crisis in the country back in 2003 and their political connections to the government. However, we saw changes in how the interviewees from the banks were able to assist us in releasing some of the aforementioned politically sensitive information. This coincided with Myanmar's political transition from 2010 onward, from an autocratic to a democratic-style political leadership. The financial sector itself has become more liberalised through enacting new laws that give banks more power to make their own decisions. Similarly, we could not conclude that the changes in the political and institutional environment are the only factor contributing to our efforts to understand how the regulations were internalised by the interviewees. Along with the changes in the political systems, we adapted our research approach as we became more familiar with the interviewees. Therefore, we cannot merely assume that changes in the institutional environment made our research easier. In emerging markets like Myanmar, we cannot ignore the high degree of structural and cultural continuity left behind by the past regimes in organisations (Grancelli, 1995). 


\section{Conclusions}

In this paper, we could not provide all the finding that we gathered in all phases of the research process. Even with the same method used, we gathered different results based on the contextual set-up. It would have been more enlightening to present our findings with the respondents' affiliations with different banks' ownership structures including state-owned and private owned banks revealed. Due to anonymity clauses, we cannot present the full picture as well. Nevertheless, our paper makes two interrelated contributions to management and organisational research in emerging markets.

First, it demonstrates the power of the reflective process and problematisation in identifying practical research questions that could enable a researcher to get closer to understanding the actual organisational and management practices in an opaque institutional environment. Previously, Alvesson and Sandberg (2011) suggested problematisation as an approach used to formulate research questions, however, there has been very limited empirical demonstration focused on how it can be actually applied. Their conceptualisation of problematisation is similar to Dewey's pragmatism, which advocates for 'learning by thinking on experience'. They see problems or errors as part of a learning process which requires reflecting upon possible lines of actions to respond to them. This is important because researchers often do not modify their research questions in response to the indeterminate situations that they encounter during their fieldwork. Social science researchers often would exclude or abandon particular contexts in their studies mainly because of the lack of data and obstacles they encounter in the data collections. This has created challenges for researchers to identify what the appropriate research questions are to study in a context, leading them to replicate studies which do not reflect the practice (Alvesson and Sandberg, 2014).

As a result, they may be taking on paradigmatic positions that correspond to research questions, but such an approach does not allow them to understand the organisational and management practices. In this paper, we used Myanmar as an example to illustrate that conducting research and developing practical research questions in an ambiguous context with high institutional power can be challenging. Similar to the other emerging and transitional economies, Myanmar has been isolated from the international research communities for decades, limiting our understanding of its politically sensitive socio-economic context. By incorporating Schon's (2017) reflective model to our research design, we highlighted that research designs in emerging markets need to consider the historical conditions, preexisting institutional limitations and legacies left behind by the past regimes. Thus, we would like to emphasise that we should not limit ourselves unreflectively to a singular paradigmatic view. We are not criticising the dominant research paradigms or promoting pragmatism as superior. Instead, we should allow ourselves to reflect on the challenges that we face in fieldwork and question whether the research questions that we pose in the beginning of a research journey are appropriate to the context in order to capture accurately the phenomena we are researching upon.

In addition, we have underlined the need for a researcher to become part of the institutional landscape prevalent in the context that is being studied. In most of the qualitative research that was previously conducted in organisational and management research, the researchers tend to act as a foreigner/outsider to the context being studied irrespective of the epistemological positions that they have taken. It took us a significant amount of time to reflect on our research methods and the outcomes associated with them in order to identify appropriate research questions and appropriate methodologies that would enable us to explore the different layers of an experiential world (Dewey, 1925). However, the reflective approach allowed us to understand that the originally chosen methodology may not be suitable to observe and measure the different contextual layers. As a researcher, we may sometimes need to take an unconventional approach if we were to uncover interesting research questions or get insights into ambiguous and highly institutionalised contexts. As shown in Figure 3, during our research journey from 2008 to 2016 in Myanmar, our research questions evolved alongside our shift in paradigmatic positioning. As noted by Sun et al. (2011) and Wright et al. (2005), emerging and transition economies are fertile grounds for testing existing and developing new theories. However, if we are not reflecting on our research process or if we avoid taking adequate responses to the indeterminate situations in our field work, we will replicate similar studies akin to past studies in the field. This limits in our potential to uncover practical research questions and issues that are unusual, unique and insightful. The reflective 
process will allow for context-informed theory-building and theory-testing rather than merely applying the Western management theories, which may not adapt well in emerging markets' contexts (Meyer, 2006).

\section{References}

ALVESSON, M. 2003. Beyond Neopositivists, Romantics, and Localists: A Reflexive Approach to Interviews in Organizational Research. The Academy of Management Review, 28, 13-33.

ALVESSON, M. \& SANDBERG, J. 2011. Generating Research Questions Through Problematization. Academy of Management Review, 36.

ALVESSON, M. \& SANDBERG, J. 2014. Habitat and Habitus: Boxed-in versus Box-Breaking Research. Organization Studies, 35, 967-987.

BAILEY, J. R., SAPARITO, P., KRESSEL, K., HRISTENSEN, E. \& HOOIJBERG, R. 1997. A Model for Reflective Pedagogy. Journal of Management Education, 21, 155-167.

BARR, R. D., BARTH, J. L. \& SHERMIS, S. S. 1977. Defining the social studies, National Council for the Social Studies.

BECK, T. \& DEMIRGUC-KUNT, A. 2006. Small and medium-size enterprises: Access to finance as a growth constraint. Journal of Banking \& finance, 30, 2931-2943.

BIESTA, G. 2010. SAGE Handbook of Mixed Methods in Social \&amp; Behavioral Research. 2 ed. Thousand Oaks, California: SAGE Publications, Inc.

BISSINGER, J. 2014. Myanmar's Economic Institutions in Transition. Journal of Southeast Asian Economics, 31, 241-55.

BORBASI, S., JACKSON, D. \& WILKES, L. 2005. Fieldwork in nursing research: positionality, practicalities and predicaments. Journal of Advanced Nursing, 51, 493-501.

BOYATZIS, R. E. 1998. Transforming Qualitative Information: Thematic Analysis and Code Development, SAGE Publications.

BURNS, S. \& BULMAN, C. 2000. Reflective Practice in Nursing: The Growth of the Professional Practitioner, Blackwell Science.

CARNOCHAN, S., SAMPLES, M., MYERS, M. \& AUSTIN, M. J. 2013. Performance Measurement Challenges in Nonprofit Human Service Organizations. Nonprofit and Voluntary Sector Quarterly, 43, 1014-1032.

COASE, R. H. 1992. The Institutional Structure of Production. The American Economic Review, 82, 713-719.

CRESWELL, J. W. 2003. Research design: qualitative, quantitative, and mixed method approaches, Sage Publications.

CRESWELL, J. W. \& CLARK, V. L. P. 2017. Designing and Conducting Mixed Methods Research, SAGE Publications.

DAFT, R. L. \& LEWIN, A. Y. 2008. Perspective-Rigor and Relevance in Organization Studies: Idea Migration and Academic Journal Evolution. Organization Science, 19, 177-183.

DENZIN, N. K. \& LINCOLN, Y. S. 2000. Introduction: The discipline and Practice of Qualitative Research. In: DENZIN, N. K. \& LINCOLN, Y. S. (eds.) Handbook of Qualitative Research. London: Sage.

DENZIN, N. K. \& LINCOLN, Y. S. 2011. The SAGE Handbook of Qualitative Research, SAGE Publications.

DEWEY, J. 1925. Experience and Nature, Whitefish, MT, Kessinger.

DEWEY, J. 1933. How we think: a restatement of the relation of reflective thinking to the educative process, D.C. Heath and company.

DEWEY, J. 1937. Democracy and Education: An Introduction to the Philosophy of Education, Macmillan.

DEWEY, J. 2002. Human Nature and Conduct, Dover Publications.

DIMAGGIO, P. J. \& POWELL, W. W. 1983. The Iron Cage Revisited: Institutional Isomorphism and Collective Rationality in Organizational Fields. American Sociological Review, 48, 147-160. 
ELKELISH, W. W. \& HASSAN, M. K. 2015. Corporate governance disclosure and share price accuracy. Journal of Applied Accounting Research, 16, 265-286.

EVERED, R. \& LOUIS, M. R. 1981. Alternative Perspectives in the Organizational Sciences: "Inquiry from the inside" and "Inquiry from the outside". The Academy of Management Review, 6, 385-395.

FEILZER, M. Y. 2009. Doing Mixed Methods Research Pragmatically: Implications for the Rediscovery of Pragmatism as a Research Paradigm. Journal of Mixed Methods Research, 4, 6-16.

GIBBS, G. 1988. Learning by Doing: A Guide to Teaching and Learning Methods, FEU.

GIOIA, D. A., CORLEY, K. G. \& HAMILTON, A. L. 2012. Seeking Qualitative Rigor in Inductive Research: Notes on the Gioia Methodology. Organizational Research Methods, 16, 15-31.

GRANCELLI, B. 1995. Organizational Change: Towards a New East-West Comparison. Organization Studies, 16, 1-25.

GRANLUND, M. \& LUKKA, K. 2010. The roles and effects of paradigms in accounting research. Management Accounting Research, 21, 110-115.

GRAY, D. E. 2017. Doing Research in the Real World, SAGE Publications.

GROSS, N. 2018. Pragmatism and the study of large-scale social phenomena. Theory and Society, 47, 87-111.

GUBA, E. G. \& LINCOLN, Y. S. 1994. Competing paradigms in qualitative research. In: DENZIN, N. K. \& LINCOLN, Y. S. (eds.) Handbook of qualitative research London: Sage.

HASSAN, M. K. 2008. The development of accounting regulations in Egypt: Legitimating the International Accounting Standards. Managerial Auditing Journal, 23, 467-484.

HASSAN, M. K., SANCHEZ, B., NGENE, G. M. \& ASHRAF, A. 2012. Financial Liberalization and Foreign Bank Entry on the Domestic Banking Performance in MENA Countries. African Development Review, 24, 195-207.

HAWORTH, K. 2006. The dynamics of power and resistance in police interview discourse. Discourse \& Society, 17, 739-759.

HÉBERT, C. 2015. Knowing and/or experiencing: a critical examination of the reflective models of John Dewey and Donald Schön. Reflective Practice, 16, 361-371.

HOLSTEIN, J. A. \& GUBRIUM, J. F. 2005. Interpretive Practice and Social Action. In: DENZIN, N. K. \& LINCOLN, Y. S. (eds.) Handbook of Qualitative Research. London: Sage.

JOHNSON, S., BOONE, P., BREACH, A. \& FRIEDMAN, E. 2000. Corporate governance in the Asian financial crisis. Journal of Financial Economics, 58, 141-186.

KEEVERS, L. \& TRELEAVEN, L. 2011. Organizing practices of reflection: A practice-based study. Management Learning, 42, 505-520.

KEIGHTLEY, E. 2010. Remembering research: memory and methodology in the social sciences. International Journal of Social Research Methodology, 13, 55-70.

KOLB, D. A. 1984. Experiential Learning, Englewood Cliffs, NJ, Prentice Hall.

KORYBKO, A. 2015. Myanmar's Color Revolution and Mysterious "Soft Coup" Attempt [Online]. Centre for Research on Globalization. [Accessed 2015].

KUBO, K. 2012. Trade Polices and Trade Misreporting in Myanmar. ASEAN Economic Bulleting, 29, 146-59.

KUHN, T. S. \& HACKING, I. 2012. The Structure of Scientific Revolutions: 50th Anniversary Edition, University of Chicago Press.

KUIT, J. A., REAY, G. \& FREEMAN, R. 2001. Experiences of Reflective Teaching. Active Learning in Higher Education, 2, 128-142.

LAFFONT, J. Competition, information and development. Annual World Bank Conference on Development Economics, 1998. 237-257.

LARSSON, M., PETTERSSON, C., ERIKSSON, C. \& SKOOG, T. 2016. Initial motives and organizational context enabling female mentors' engagement in formal mentoring - A qualitative study from the mentors' perspective. Children and Youth Services Review, 71, 17-26. 
LI, J. 2008. Ethical Challenges in Participant Observation: A Reflection on Ethnographic Fieldwork. The Qualitative Report, 13.

MALMI, T. 2010. Reflections on paradigms in action in accounting research. Management Accounting Research, 21, 121-123.

MEYER, K. E. 2006. Asian management research needs more self-confidence. Asia Pacific Journal of Management, 23, 119-137.

MORGAN, D. L. 2007. Paradigms Lost and Pragmatism Regained: Methodological Implications of Combining Qualitative and Quantitative Methods. Journal of Mixed Methods Research, 1, 4876.

NANYONDO, M., TAURINGANA, V., KAMUKAMA, N. \& NKUNDABANYANGA, S. 2014. Quality of financial statements, information asymmetry, perceived risk and access to finance by Ugandan SMEs. International Journal of Management Practice, 7, 324-340.

NEHRU, V. 2015. Developing Myanmar's Finance Sector to Support Rapid, Inclusivve and Sustainable Economic Growth. ADB Economics Working Paper Series. Manila, Philippines: Asian Development Bank.

NEUMAN, W. L. 2000. Social Research Methods: Qualitative and Quantitative Approaches, Allyn \& Bacon, Incorporated.

OLIVER, C. 1991. Strategic Responses to Institutional Processes. The Academy of Management Review, 16, 145-179.

QUATTRONE, P. 2009. 'We have never been Post-modern': On the Search of Management Accounting Theory. European Accounting Review, 18, 621-630.

RAPLEY, T. J. 2001. The art(fulness) of open-ended interviewing: some considerations on analysing interviews. Qualitative Research, 1, 303-323.

RIACH, K. 2009. Exploring Participant-centred Reflexivity in the Research Interview. Sociology, 43, 356-370.

ROSS, E. W. \& LYNNE, M. H. 1986. Towards a Critical Theory of Reflective Inquiry: Theme. Journal of Teacher Education, 37, 9-15.

SANDBERG, J. \& ALVESSON, M. 2011. Ways of constructing research questions: gap-spotting or problematization? Organization, 18, 23-44.

SCHON, D. A. 1987. Educating the Reflective Practitioner: Toward a New Design for Teaching and Learning in the Professions, Wiley.

SCHÖN, D. A. 2017. The Reflective Practitioner: How Professionals Think in Action, Taylor \& Francis.

SHAPIRO, D. L., VON GLINOW, M. A. \& XIAO, Z. 2007. Toward Polycontextually Sensitive Research Methods. Management and Organization Review, 3, 129-152.

SIMONDS, V. W. \& CHRISTOPHER, S. 2013. Adapting Western Research Methods to Indigenous Ways of Knowing. American Journal of Public Health, 103, 2185-2192.

SINGH, A. 2003. Competition, corporate governance and selection in emerging markets*. The Economic Journal, 113, F443-F464.

STARBUCK, W. H. 2006. The Production of Knowledge:The Challenge of Social Science Research: The Challenge of Social Science Research, OUP Oxford.

STOIAN, M.-C., DIMITRATOS, P. \& PLAKOYIANNAKI, E. 2018. SME internationalization beyond exporting: A knowledge-based perspective across managers and advisers. Journal of World Business, 53, 768-779.

SUN, P., MELLAHI, K. \& LIU, G. S. 2011. Corporate governance failure and contingent political resources in transition economies: A longitudinal case study. Asia Pacific Journal of Management, 28, 853-879.

TASHAKKORI, A. \& TEDDLIE, C. 1998. Mixed Methodology: Combining Qualitative and Quantitative Approaches, SAGE Publications.

THAN, T. M. M. 2014. Introductory Overview: Myanmar's Economic Reforms. Journal of Southeast Asian Economics, 31, 165-72.

TRUMAN, E. M. 2006. Reform of the IMF for the 21st Century, Columbia University Press. 
TSANG, E. W. K. 2009. Chinese Management Research at a Crossroads: Some Philosophical Considerations. Management and Organization Review, 5, 131-143.

TSUI, A. S. 2007. From Homogenization to Pluralism: International Management Research in the Academy and Beyond. The Academy of Management Journal, 50, 1353-1364.

TURNELL, S. 2011. Fundamentals of Myanmar's Macroeconomy: A Political Economy Perspective. Asian Economic Policy Review, 6, 136-153.

WATSON, T. J. 2011. Ethnography, Reality, and Truth: The Vital Need for Studies of 'How Things Work' in Organizations and Management. Journal of Management Studies, 48, 202-217.

WELCH, C., PIEKKARI, R., PLAKOYIANNAKI, E. \& PAAVILAINEN-MÄNTYMÄKI, E. 2011. Theorising from case studies: Towards a pluralist future for international business research. Journal of International Business Studies, 42, 740-762.

WICKS, A. C. \& FREEMAN, R. E. 1998. Organization Studies and the New Pragmatism: Positivism, Anti-Positivism, and the Search for Ethics. Organization Science, 9, 123-140.

WIN, S. 2013. Challenges of Conducting Field Research in Myanmar (Burma): In the Context of Banking. Project Southeast Asia. Oxford, United Kingdom. .

WIN, S. 2018. Banks' lending behaviour under repressed financial regulatory environment: In the context of Myanmar. Pacific Accounting Review, 30, 20-34.

WORLD BANK 2013. World Bank Group to Support Myanmar's Plan to Improve People's Access to Electricity. The World Bank.

WRIGHT, M., FILATOTCHEV, I., HOSKISSON, R. E. \& PENG, M. W. 2005. Strategy Research in Emerging Economies: Challenging the Conventional Wisdom*. Journal of Management Studies, 42, 133.

WU, Y.-C., WEI KIONG TING, I., LU, W.-M., NOURANI, M. \& KWEH, Q. L. 2016. The impact of earnings management on the performance of ASEAN banks. Economic Modelling, 53, 156-165.

XUEGONG, S. \& XUEYUAN, L. 2011. Small and medium enterprises' access to finance in china. Small and medium enterprises (SMEs) access to finance in selected East Asian Economies. Indonesia: ERIA Research Project Report. 11_China, 351-384.

YANOW, D. \& TSOUKAS, H. 2009. What is Reflection-In-Action? A Phenomenological Account. Journal of Management Studies, 46, 1339-1364.

\footnotetext{
' In Burmese culture, it is common to address a senior as either uncle or brother. In this case, the interviewer was of the same age as her parents, she called him as 'uncle'.

ii In culture, it is common to put a title 'Ko' in front of the name of a person for respect if they are of the same age.
} 